\title{
A procedure for correcting readings in chemiluminescence nitrogen oxide analyzers due to the effect of sample pressure
}

\author{
M. Doval ${ }^{1}$, J. Barberá ${ }^{1}$, E. González ${ }^{1} \&$ F. J. Marzal ${ }^{2}$ \\ ${ }^{I}$ Department of Chemical Engineering, University of Murcia, Spain \\ ${ }^{2}$ Department of Thermical Engineering and Fluids, \\ University of Cartagena, Spain
}

\begin{abstract}
The influence of sample pressure on chemiluminescence nitrogen oxides analyzers is studied in this paper. Although both of the employed analyzers comply with the requirements established in the standard EN 14211:2005 for this performance feature, it is advisable to make corrections to ensure a better quality of the data. The proposed procedure reduced to $\pm 1.5 \%$ the mistakes caused by the effect of sample pressure.
\end{abstract}

Keywords: EN 14211:2005, nitrogen oxides, chemiluminiscence, pressure, correction procedure.

\section{Introduction}

Networks measuring ambient air pollution within the Member States use, in general, analyzers certified by the Environmental Protection Agency of the United States as reference methods [2], although no European legislation in this matter obliges the analyzers to meet any special requirements, except as regards the analytical method employed.

In order to improve emission quality data, the European Commission has elaborated the Proposal for a Directive on ambient air and cleaner air for Europe [3], which will replace the Framework Directive 96/62/EC [4] currently in force. The Proposal establishes new reference documents for the measurement of the gaseous pollutants regulated in this field.

Nitrogen oxides ( $\mathrm{NO}$ and $\mathrm{NO}_{2}$ ) receive special attention due to their effects on humans and the environment and for being tropospheric ozone precursors. The reference method for the measurement of these pollutants established in the 
Proposal of Directive is that described in EN 14211:2005 [1], which will replace the current document in force (ISO 7796:1985 [5]). The analytical method is the same in both documents, that is, the chemiluminescence reaction between NO and $\mathrm{O}_{3}$ which has been widely studied in the literature [6-9], but the new standard sets a number of requirements to be met by the nitrogen oxides analyzers before they can obtain the so-called "Type-Approval" certificate. The aforementioned requirements consist of several tests in the laboratory and field and calculation of the expanded uncertainty, which has to be lower than that specified in the legislation $( \pm 15 \%)$.

The performance characteristics in the laboratory and field are multiple and, among them, the response time, short and long term drift or the influence of pressure and temperature samples are evaluated. In this paper, results concerning the influence of sample pressure are discussed. A correction procedure for the readings is proposed in order to improve data quality.

\section{Experimental section}

An in-house designed test chamber was used to reproduce the tests described in EN 14211:2005 regarding sample pressure, and those carried out to obtain a procedure for correcting the readings.

NO was used for the tests as indicated in EN 14211:2005 in order to eliminate the possible effect of converter efficiency on the results. Gaseous standards were generated by mixing known flow rates of zero air (produced in the laboratory by compression and purification of ambient air) with known flow rates of a mixture of $50.3 \mathrm{ppm}$ of $\mathrm{NO}$ in $\mathrm{N}_{2}$ matrix from a cylinder. Measurement and control of the flows were made possible by using mass flow controllers. The system is placed inside a thermically isolated chamber operating in the range of 0 to $30^{\circ} \mathrm{C}$. Different pressures in sample line were achieved by means of regulating valves, fig. 1. The analyzers were calibrated at $20^{\circ} \mathrm{C}$ and ambient pressure (for both surrounding air and sample flow). Higher pressures than the ambient are obtained by partially closing the valve located in the main line (V1), whereas lower pressures are achieved by closing V2.

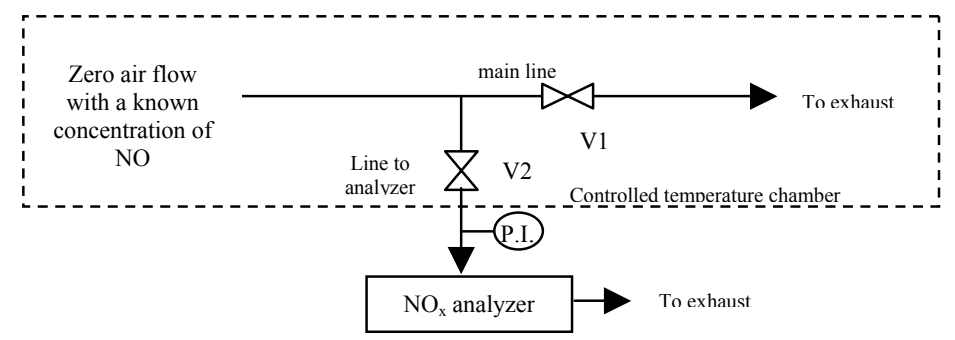

Figure 1: Basic diagram of the experimental device used for the tests.

\subsection{Pressure influence test described in EN 14211:2005}

First, tests regarding the calculation of the sensitivity coefficient to sample pressure, $b_{g p}$, were carried out. Two different chemiluminescence nitrogen 
dioxides analyzers were used. The test is carried out with $770 \mathrm{ppb}$ NO in zero air (which corresponds to $80 \%$ of the upper range of NO certification set by the Standard, $961 \mathrm{ppb})$. The abovementioned mixture is introduced in the analyzer at an absolute pressure of $80 \mathrm{kPa}$ and, afterwards, at $110 \mathrm{kPa}$, the readings being recorded in both situations. Sample and ambient temperatures are kept at $20^{\circ} \mathrm{C} \pm$ $0.5^{\circ} \mathrm{C}$ and $20^{\circ} \mathrm{C} \pm 2^{\circ} \mathrm{C}$, respectively, during the tests.

From eqn (1), $b_{g p}(p p b / k P a)$ can be calculated, where $C_{P 1}$ and $C_{P 2}$ are the average reading concentrations at sample pressure $\mathrm{P}_{1}(80 \mathrm{kPa})$ and $\mathrm{P}_{2}(11 \mathrm{kPa})$, respectively.

$$
b_{g p}=\left|\frac{\left(C_{P 1}-C_{P 2}\right)}{P_{2}-P_{1}}\right|
$$

The performance criterion for this parameter is $\mathrm{b}_{\mathrm{gp}} \leq 8 \mathrm{ppb} / \mathrm{kPa}$.

\subsection{Pressure influence at the hourly limit value}

The concentration established in EN 14211:2005 (770 ppb) is much higher than that found in ambient air. This is why the pressure influence was evaluated at a concentration of $\mathrm{NO}$ and $\mathrm{NO}_{2}$ close to the hourly limit value for $\mathrm{NO}_{2}(105 \mathrm{ppb})$. The rest of the conditions of the tests remained the same.

\subsection{Tests for obtaining a correction procedure of the readings}

Correlations between NO readings and NO standard generated concentrations at different pressures were made. These tests were carried out at $0,50,100,150$, 200 and $250 \mathrm{ppb}$ as concentrations higher than the last value are not expected to be found in ambient air. Relative sample pressure was set at 19.6, 14.7, 9.8, 4.9, $0,-4.9,-9.8,-14.7$ and $-16.6 \mathrm{kPa}$. For this set of experiments only Analyzer I was employed.

\section{Results and discussion}

\subsection{Pressure influence test described in EN 14211:2005}

Figure 2 shows the results obtained when reproducing the sample pressure test described in 2.1. In both cases, pressure was seen to influence the readings. The sensitivity coefficient, $b_{\mathrm{gp}}$, for Analyzer I is $4.8 \mathrm{ppb} / \mathrm{kPa}$, whereas that calculated $\mathrm{b}_{\mathrm{gp}}$ for Analyzer II is $7.9 \mathrm{ppb} / \mathrm{kPa}$, so both of them meet the performance criterion for this test $(8 \mathrm{ppb} / \mathrm{kPa})$. A summary of the calculated coefficients is given in table 1 together with the value of $b_{\mathrm{gp}}$ expressed in percentage of deviation $/ \mathrm{kPa}$.

\subsection{Pressure influence at the hourly limit value}

Table 2 shows the results when repeating the test for $\mathrm{NO}(108 \mathrm{ppb})$ and for $\mathrm{NO}_{2}$ (108 ppb) with Analyzer I. The deviation in both channels is the same. The percentual variation of the readings with pressure does not depend on concentration as can be seen by comparing tables 1 and 2 . 
Table 1: $\quad b_{\mathrm{gp}}$ coefficients calculated according to EN 14211:2005 for two different nitrogen dioxide analyzers.

\begin{tabular}{cccc}
\hline \multicolumn{2}{c}{ ANALYZER I } & \multicolumn{2}{c}{ ANALYZER II } \\
\hline$b_{g p}(\mathrm{ppb} / \mathrm{kPa})$ & $b_{g p}(\%$ of change $/ \mathrm{kPa})$ & $b_{g p}(\mathrm{ppb} / \mathrm{kPa})$ & $\begin{array}{c}b_{g p}(\% \text { of } \\
\text { change } / \mathrm{kPa})\end{array}$ \\
\hline 4.8 & 0.62 & 7.9 & 1.02 \\
\hline
\end{tabular}
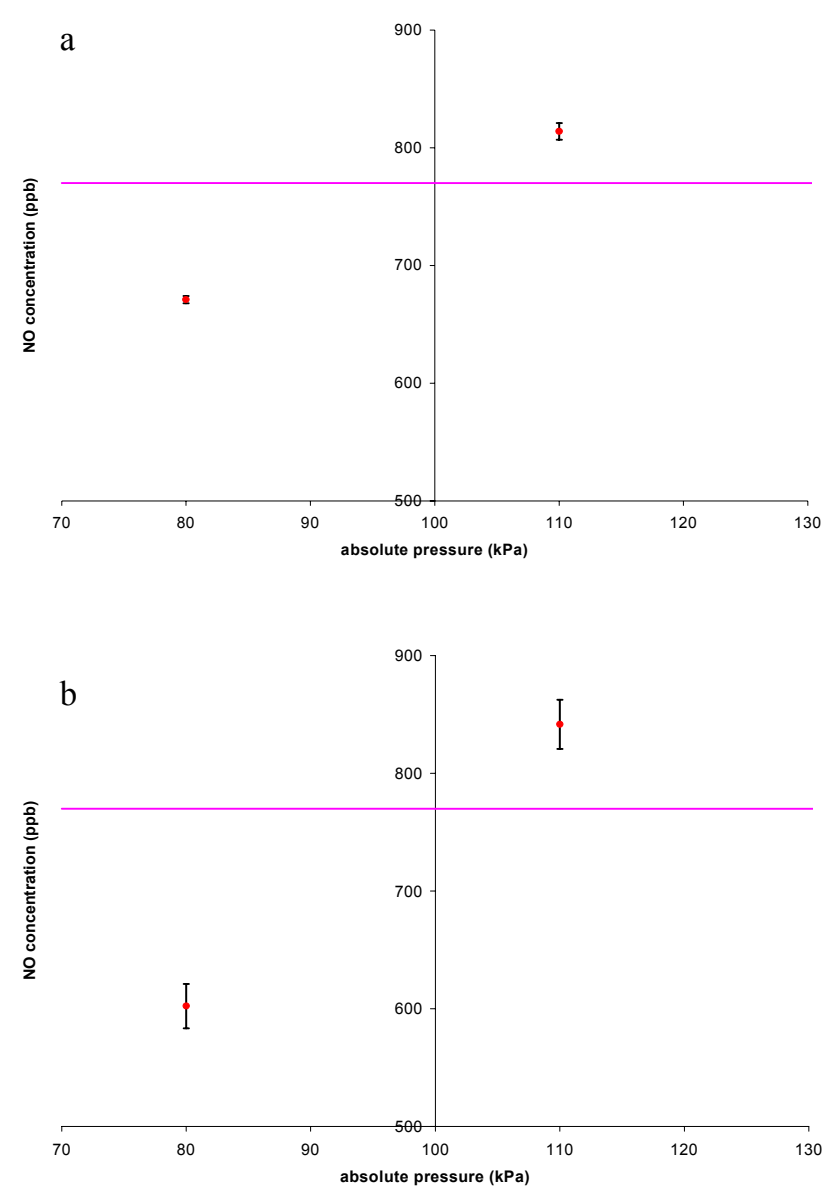

Figure 2: Deviation in NO readings through effect of pressure sample. The continuous line represents the standard generated concentration in the test chamber (770 ppb). (a) Analyzer I. (b) Analyzer II.

\subsection{Correction procedure of the readings by effect of pressure}

In practice, analyzers are calibrated in situ in the measuring ambient air pollution networks by means of pressure cylinders using an exhaust outlet to prevent the 
analyzers from overpressuring, although the sample will always be at a higher pressure than the ambient one. On the other hand, while analyzers are measuring the ambient air, a drop in pressure is created in the sample line. When line maintenance is not appropriate, it can become blocked for different reasons, and the depression will increase. All of this can lead to sample pressure differences from calibration to measurement ranging from a few tenths of $\mathrm{kPa}$ to more than the exit pressure of the pressure reducer in the worst situation.

Table 2: $\quad b_{\mathrm{gp}}$ coefficients calculated using $108 \mathrm{ppb}$ of NO and $105 \mathrm{ppb}$ of $\mathrm{NO}_{2}$

\begin{tabular}{|c|c|c|c|}
\hline \multicolumn{4}{|c|}{ ANALYZER I } \\
\hline \multicolumn{2}{|c|}{$108 \mathrm{ppb}$ de NO } & \multicolumn{2}{|c|}{$102 \mathrm{ppb}$ de $\mathrm{NO}_{2}$} \\
\hline$b_{g p}(\mathrm{ppb} / \mathrm{kPa})$ & $b_{g p}(\%$ of change $/ \mathrm{kPa})$ & $b_{g p}(\mathrm{ppb} / \mathrm{kPa})$ & $\begin{array}{c}b_{g p}(\% \text { of } \\
\text { change } / \mathrm{kPa})\end{array}$ \\
\hline 0.63 & 0.58 & 0.59 & 0.58 \\
\hline
\end{tabular}

As checked in previous tests, changes in sample pressure lead to concentration reading variations. For this reason, many analyzers have an option called "pressure compensation" in order to avoid these mistakes but, although data quality is improved, it is not enough to avoid differences of up to $\pm 12 \%$, in some cases.

A number of experiments were designed consisting of generating different NO concentrations ranging from zero to $250 \mathrm{ppb}$ at different sample pressures and measuring them with the Analyzer I. Figure 3 shows the readings obtained when generating different NO concentrations at each pressure. The analyzer was calibrated at $20^{\circ} \mathrm{C}$ and ambient pressure (for both surrounding air and sample flow).

When working at a different sample pressure from that of the calibration conditions and no equation for its respective line is available (eqn (2)) it can be estimated from the slopes and y-intercepts of the straight lines in figure 3 . As the $\mathrm{y}$-intercept does not follow any mathematical law with pressure, an averaged $y$ intercept, $A$, was calculated. Slopes at different pressures, $B$, are calculated from figure 4 .

$$
[\mathrm{NO}]_{\text {reading }}=\mathrm{A}+\mathrm{B} \cdot[\mathrm{NO}]_{\text {standard }}
$$

It is convenient to correlate the slope versus an internal parameter of the analyzer, such as the chamber pressure or the sample line flow, which changes proportionally to sample line pressure in order to avoid incorporating a pressure meter in the line. Figure 5 shows the relation between the calculated slope and the sample line flow.

Once the slope is known, it is possible to correct the analyzer readings by eqn (3).

$$
[N O]_{\text {corrected }}=\frac{[N O]_{\text {reading }}^{\prime}-A}{B}
$$

Before using eqn (3), it is advisable to first correct the NO readings with the calibration curve of the analyzer calculated from at least 6 points in the 
calibration conditions (in this example, at $20{ }^{\circ} \mathrm{C}$ and ambient pressure), giving the [NO]' reading.

Table 3 shows the mistakes of the readings when no correction for the pressure effect is made, just the correction mentioned in the above paragraph, and those after correction has been made.

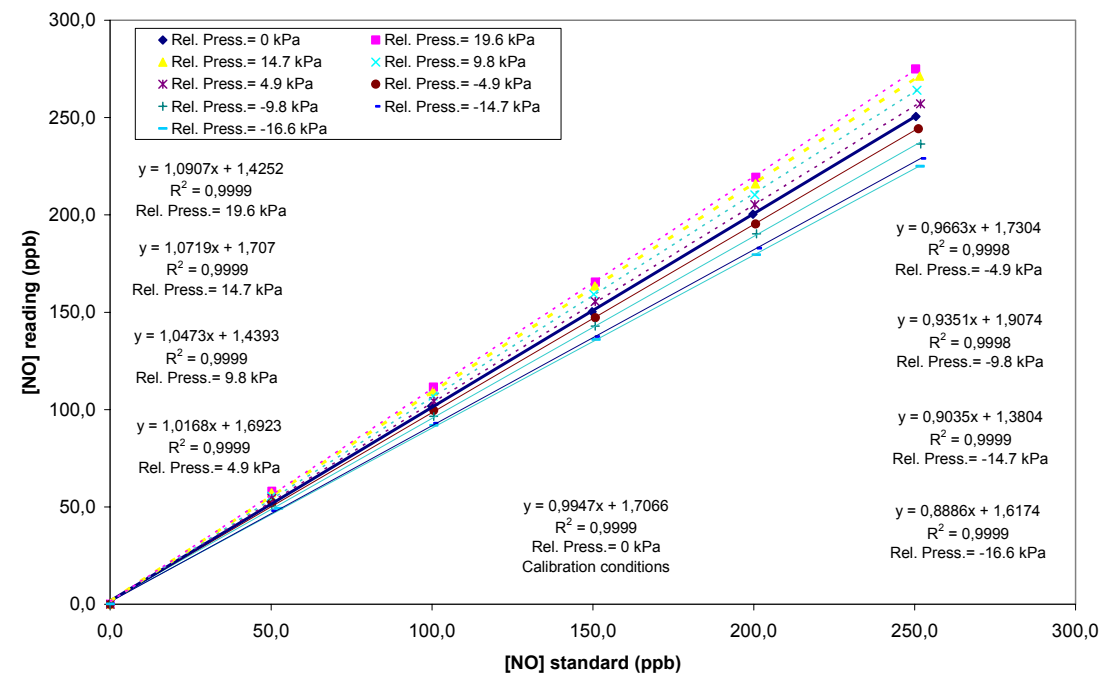

Figure 3: $\quad$ Reading changes as a function of sample pressure.

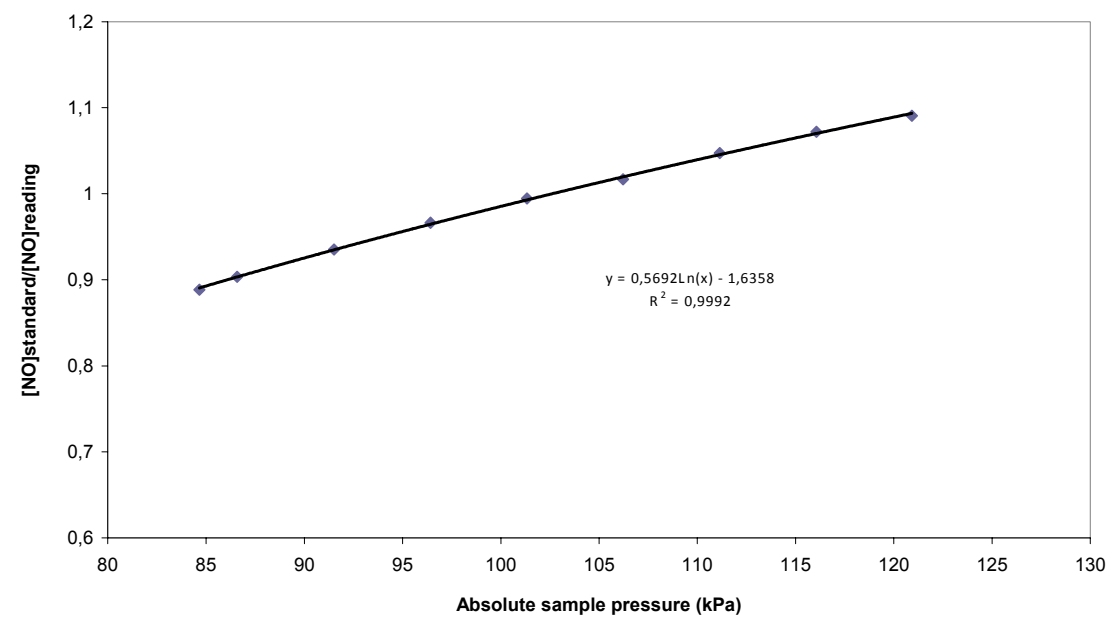

Figure 4: $\quad$ Estimation of the slope of eqn (2) from sample line pressure. 


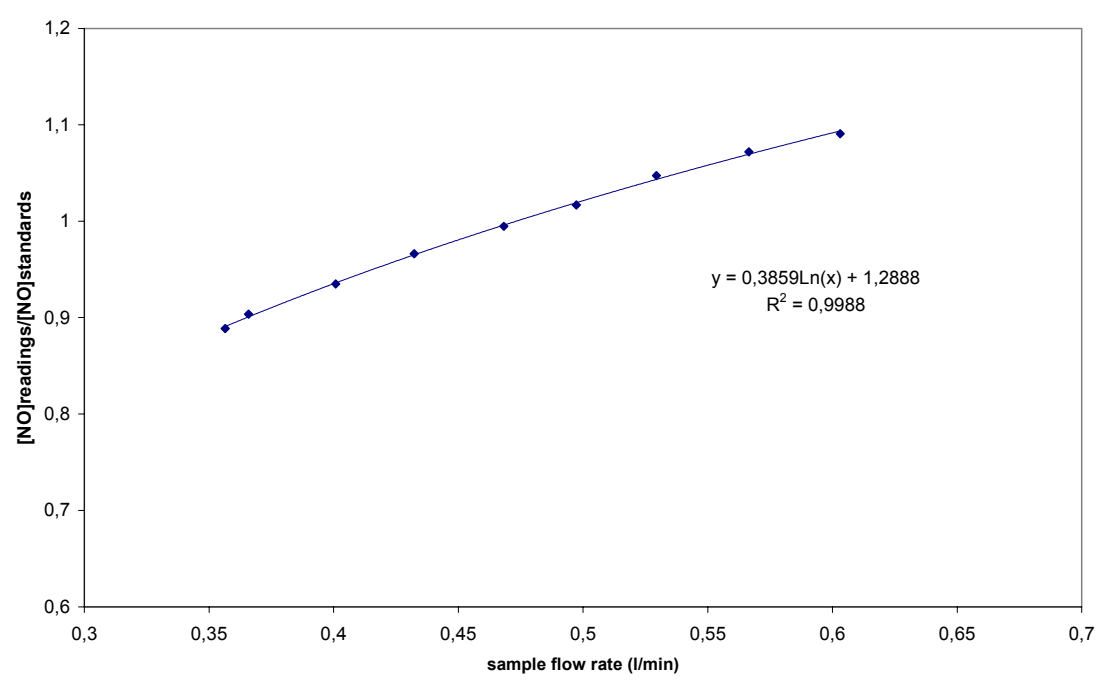

Figure 5: $\quad$ Estimation of the slope of eqn (2) from sample line flow.

The proposed correction improves the data in all cases except four (table 3, in bold) and maximum deviation is below $\pm 1.5 \%$. Figure 6 shows a chart where the mistakes due to the effect of sample pressure are represented depending on the concentration level. The dashed lines delimit the region where correction is not necessary. Outside this region, correction is highly recommended.

Deviations from the standard generated concentration are constant at high concentrations for a fixed sample pressure but at lower concentrations the deviation can be higher or lower. This is due to the intrinsic mistakes of the calibration curve in the calibration conditions, which are higher and positive in the example at low concentrations. Higher sample pressures than the calibration pressure give higher responses than the "real" ones, increasing the mistake at low concentrations. When sample line pressure is lower than that used for calibration, the readings are lower than "real" ones, partially compensating the calibration mistake in these concentration levels.

\section{Conclusions}

In this paper the influence of sample line pressure on chemiluminescence nitrogen oxides analyzers has been studied. When the pressure difference between calibration and operating conditions is about $15 \mathrm{kPa}$, mistakes of $\pm 10 \%$ are found. These differences of pressure occur as a result of the calibration procedure (overpressure) and the operation conditions (depression).

The proposed correction for the data regarding pressure consists on the following steps:

1. Calibrate the analyzer in known conditions (e.g. $20^{\circ} \mathrm{C}$ and atmospheric pressure). Introduce at least 6 values of concentration (zero included). 
Table 3: $\quad$ Comparison of mistakes with and without correction due to sample pressure.

\begin{tabular}{|c|c|c|c|c|c|c|c|}
\hline $\begin{array}{c}\text { Sample } \\
\text { pressure } \\
(\mathrm{kPa})\end{array}$ & $\begin{array}{l}\text { Sample } \\
\text { line flow } \\
(1 / \mathrm{min})\end{array}$ & $\begin{array}{l}{[\mathrm{NO}]_{\text {standard }}} \\
(\mathrm{ppb})\end{array}$ & $\begin{array}{c}{[\mathrm{NO}]_{\text {reading }}} \\
\text { (ppb) }\end{array}$ & $\begin{array}{c}\text { [NO]' }{ }^{\text {reading }} \\
\text { (ppb) }\end{array}$ & $\begin{array}{c}\text { Deviation } \\
\text { of } \\
\text { [NO]' reading } \\
(\%)\end{array}$ & $\begin{array}{c}{[\mathrm{NO}]_{\text {corrected }}} \\
(\mathbf{p p b})\end{array}$ & $\begin{array}{c}\text { Deviation } \\
\text { of } \\
{[\mathrm{NO}]_{\text {corrected }}} \\
(\%)\end{array}$ \\
\hline 101.325 & 0.468 & 250.4 & 250.5 & 250.1 & -0.10 & 249.5 & -0.35 \\
\hline 101.325 & 0.468 & 199.7 & 200.3 & 199.6 & -0.06 & 198.8 & -0.47 \\
\hline 101.325 & 0.468 & 149.8 & 150.3 & 149.4 & -0.30 & 148.3 & -0.98 \\
\hline 101.325 & 0.468 & 99.9 & 101.8 & 100.6 & 0.71 & 99.4 & -0.52 \\
\hline 101.325 & 0.468 & 50.0 & 52.9 & 51.5 & 3.05 & 50.1 & 0.20 \\
\hline 101.325 & 0.468 & 0.0 & 0.3 & -1.4 & - & -3.1 & - \\
\hline 120.925 & 0.603 & 250.3 & 274.9 & 274.7 & 9.71 & 249.6 & -0.28 \\
\hline 120.925 & 0.603 & 200.6 & 219.3 & 218.7 & 9.02 & 198.5 & -1.06 \\
\hline 120.925 & 0.603 & 150.8 & 165.5 & 164.7 & 9.21 & 149.1 & -1.13 \\
\hline 120.925 & 0.603 & 100.5 & 111.5 & 110.4 & 9.88 & 99.5 & -1.01 \\
\hline 120.925 & 0.603 & 50.3 & 58.0 & 56.6 & 12.59 & 50.3 & -0.01 \\
\hline 120.925 & 0.603 & 0.0 & 0.1 & -1.7 & - & -3.0 & - \\
\hline 116.065 & 0.567 & 251.5 & 271.2 & 270.9 & 7.72 & 251.8 & 0.11 \\
\hline 116.065 & 0.567 & 200.5 & 216.0 & 215.4 & 7.45 & 199.9 & -0.29 \\
\hline 116.065 & 0.567 & 150.6 & 163.5 & 162.6 & 8.00 & 150.6 & -0.03 \\
\hline 116.065 & 0.567 & 100.4 & 109.4 & 108.3 & 7.89 & 99.7 & -0.64 \\
\hline 116.065 & 0.567 & 50.2 & 57.2 & 55.8 & 11.32 & 50.7 & 1.06 \\
\hline 116.065 & 0.567 & 0.0 & 0.2 & -1.5 & - & -2.9 & - \\
\hline 111.135 & 0.529 & 250.7 & 264.0 & 263.7 & 5.18 & 251.2 & 0.18 \\
\hline 111.135 & 0.529 & 200.3 & 210.4 & 209.8 & 4.71 & 199.5 & -0.42 \\
\hline 111.135 & 0.529 & 150.3 & 159.3 & 158.4 & 5.40 & 150.3 & -0.02 \\
\hline 111.135 & 0.529 & 100.3 & 106.9 & 105.7 & 5.37 & 99.8 & -0.57 \\
\hline 111.135 & 0.529 & 50.1 & 55.6 & 54.1 & 7.98 & 50.3 & 0.39 \\
\hline 111.135 & 0.529 & 0.0 & -0.1 & -1.8 & - & -3.2 & \\
\hline 106.225 & 0.497 & 251.8 & 257.1 & 256.7 & 1.96 & 250.3 & -0.60 \\
\hline 106.225 & 0.497 & 200.3 & 205.2 & 204.6 & 2.12 & 199.1 & -0.61 \\
\hline 106.225 & 0.497 & 150.7 & 155.5 & 154.6 & 2.57 & 150.1 & -0.42 \\
\hline 106.225 & 0.497 & 100.6 & 104.3 & 103.2 & 2.57 & 99.6 & -0.95 \\
\hline 106.225 & 0.497 & 50.3 & 54.5 & 53.0 & 5.48 & 50.4 & 0.32 \\
\hline 106.225 & 0.497 & 0.0 & 0.0 & -1.7 & - & -3.3 & - \\
\hline 96.425 & 0.432 & 251.2 & 244.2 & 243.8 & -2.95 & 250.9 & -0.11 \\
\hline 96.425 & 0.432 & 200.6 & 195.3 & 194.6 & -2.98 & 200.0 & -0.31 \\
\hline 96.425 & 0.432 & 150.8 & 147.2 & 146.3 & -3.00 & 149.9 & -0.62 \\
\hline 96.425 & 0.432 & 100.6 & 99.6 & 98.4 & -2.17 & 100.3 & -0.31 \\
\hline 96.425 & 0.432 & 50.3 & 52.2 & 50.8 & 0.92 & 50.9 & 1.22 \\
\hline 96.425 & 0.432 & 0 & 0 & -1.7 & - & -3.5 & - \\
\hline 91.515 & 0.401 & 251.9 & 236.4 & 235.9 & -6.33 & 250.3 & -0.62 \\
\hline 91.515 & 0.401 & 200.9 & 190.3 & 189.6 & -5.63 & 200.8 & -0.04 \\
\hline 91.515 & 0.401 & 150.7 & 142.9 & 141.9 & -5.81 & 149.9 & -0.52 \\
\hline 91.515 & 0.401 & 100.5 & 96.5 & 95.3 & -5.18 & 100.1 & -0.42 \\
\hline 91.515 & 0.401 & 50.2 & 50.6 & 49.2 & -2.08 & 50.8 & 1.16 \\
\hline 91.515 & 0.401 & 0 & 0 & -1.7 & - & -3.6 & - \\
\hline 86.585 & 0.366 & 252.2 & 229.0 & 228.5 & -9.40 & 251.9 & -0.13 \\
\hline 86.585 & 0.366 & 201.1 & 182.9 & 182.2 & -9.42 & 200.4 & -0.33 \\
\hline 86.585 & 0.366 & 150.8 & 137.5 & 136.5 & -9.47 & 149.8 & -0.69 \\
\hline 86.585 & 0.366 & 100.6 & 92.9 & 91.7 & -8.87 & 100.0 & -0.62 \\
\hline 86.585 & 0.366 & 50.3 & 48.0 & 46.5 & -7.48 & 49.9 & -0.86 \\
\hline 86.585 & 0.366 & 0 & 0.16 & -1.6 & - & -3.5 & - \\
\hline 84.655 & 0.357 & 251.7 & 225.0 & 224.5 & -10.81 & 250.2 & -0.60 \\
\hline 84.655 & 0.357 & 200.8 & 179.5 & 178.7 & -10.99 & 198.8 & -0.98 \\
\hline 84.655 & 0.357 & 151.0 & 136.0 & 135.0 & -10.59 & 149.7 & -0.83 \\
\hline 84.655 & 0.357 & 100.6 & 91.9 & 90.7 & -9.87 & 100.0 & -0.63 \\
\hline 84.655 & 0.357 & 52.3 & 49.3 & 47.8 & -8.51 & 51.9 & -0.78 \\
\hline 84.655 & 0.357 & 0 & 0.16 & -1.6 & - & -3.6 & \\
\hline
\end{tabular}




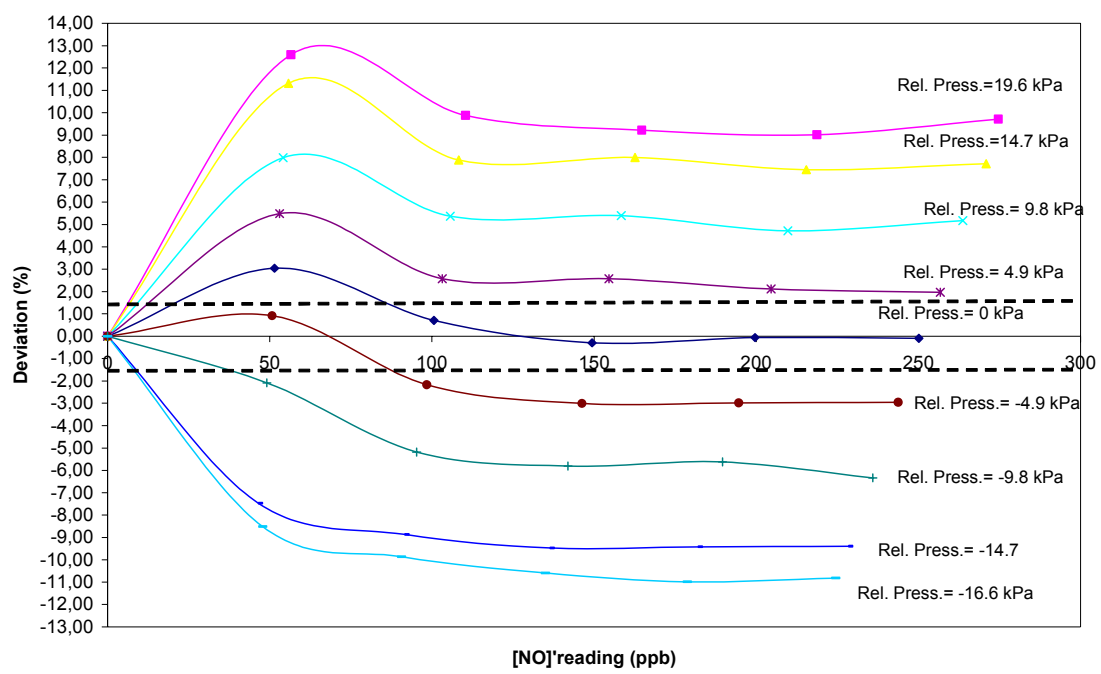

Figure 6: Chart for determining the convenience of the reading correction.

2. Generate different known concentrations of $\mathrm{NO}$ (advisable from 0 to 250 ppb) at different known sample relative pressures (from -17 to $+20 \mathrm{kPa}$ ) and record the responses. Represent the analyzer responses vs. generated concentration. Calculate an average y-intercept from those lines.

3. Represent the slopes of the above lines (NO concentration measured by the analyzer/NO generated concentration) vs. line pressure or sample flow rate.

4. Knowing the line pressure (or sample flow) it is possible to obtain a straight line, using the above graph to calculate the slope, and the average y-intercept.

5. Data obtained with the analyzer should be corrected by means of the calculated line in 4. To improve quality of the data it is advisable to correct the analyzer readings with the calibration carried out in 1 before using the correction in 4 .

The results have shown that the mistakes introduced through the effect of pressure can be reduced to $\pm 1.5 \%$. A chart is included to decide whether the correction is worth carrying out.

\section{Acknowledgements}

This work was carried out thanks to the financial support of the Consejería de Desarrollo Sostenible y Ordenación del Territorio and the Fundación Séneca of the Autonomic Community of Murcia. 


\section{References}

[1] EN 14211:2005. Ambient air quality. Standard method for the measurement of the concentration of nitrogen dioxide and nitrogen monoxide by chemiluminescence. ISBN 0580457206.

[2] United States Environmental Protection Agency. Ambient Air Monitoring Reference and Equivalent Methods. Code of Federal Regulations, Title 40, Part 53, pp 21-39, 2007.

[3] European Union. Proposal for a Directive of the European Parliament and of the Council on ambient air quality and cleaner air for Europe, 2005. http://eur-lex.europa.eu/LexUriServ/LexUriServ.do?uri=COM:2005:0447: FIN:EN:PDF

[4] European Union. Council Directive 96/62/EC on ambient air quality assessment and management. Official Journal of European Communities, OJ L 296, pp 0055-0063, 21.11.1996.

[5] ISO 7996:1985. Determination of the mass concentration of nitrogen oxides. Chemiluminescence method.

[6] Clough P.N., Thrus B.A. Mechanism of chemiluminescence reaction between nitric oxide and ozone. Trans. Faraday Soc. (1967), 63, 915-925.

[7] Mathews R.D., Sawyer R.F., Schefer R.W. Interferences in chemiluminescent measurement of $\mathrm{NO}$ and $\mathrm{NO}_{2}$ emissions from combustion systems. Environ. Sci. Technol. (1977), 11, 1092-1096.

[8] Mehrabzadeh A.A., O'Brian R.J., Hard T.M. Optimization of response of chemiluminescence analyzers. Anal. Chem. (1983), 55, 1660-1665.

[9] Winer A.M., Peters J.W., Smith J.P., Pitts J.N. Response of commercial chemiluminescent $\mathrm{NO}-\mathrm{NO}_{2}$ analyzers to other nitrogen-containing compounds. Environ. Sci. Technol. (1974), 8, 1118-1121. 